http://dx.doi.org/10.35381/racji.v5i8.572

\title{
Análisis del régimen especial de trabajo doméstico desde el principio de igualdad
} y la prohibición de discriminación

\section{Analysis of the special domestic work regime from the principle of equality and the prohibition of discrimination}

\author{
María Belén Pesantez-Cárdenas \\ maria.pesantez@psg.ucacue.edu.ec \\ Universidad Católica de Cuenca, Cuenca \\ Ecuador \\ https://orcid.org/0000-0001-9099-1300 \\ Juan Carlos Erazo-Álvarez \\ jcerazo@ucacue.edu.ec \\ Universidad Católica de Cuenca, Cuenca \\ Ecuador \\ https://orcid.org/0000-0001-6480-2270 \\ Enrique Eugenio Pozo-Cabrera \\ epozo@ucacue.edu.ec \\ Universidad Católica de Cuenca, Cuenca \\ Ecuador \\ https://orcid.org/0000-0003-4980-6403 \\ Cecilia Ivonne Narváez-Zurita \\ inarvaez@ucacue.edu.ec \\ Universidad Católica de Cuenca, Cuenca \\ Ecuador \\ https://orcid.org/0000-0002-7437-9880
}

Recibido: 12 de noviembre de 2019

Aprobado: 14 de diciembre de 2019

\section{RESUMEN}

Esta investigación presenta un enfoque general de la modalidad de trabajo doméstico desarrollado en Ecuador, mediante un análisis de su evolución histórica, reformas, tendencias y diferencias en su cobertura constitucional y legal, respecto de la generalidad de trabajadores amparados por el Código de Trabajo. De esta manera se 
busca como objetivo proporcionar una recopilación y descripción de la regulación nacional e internacional del trabajo doméstico, desde la definición de trabajo decente, y el principio de igualdad y no discriminación, como pilares para la creación de un sistema normativo justo y razonable. Para esto, se realiza una investigación cualitativa, que basada en los métodos analítico-sintético e inductivo-deductivo sea capaz de crear los cambios necesarios para el desarrollo de su protección constitucional.

Descriptores: Trabajo doméstico; Derecho constitucional; Principio de igualdad; Prohibición de discriminación; Justificación razonable.

\begin{abstract}
This research presents a general approach to the modality of domestic work developed in Ecuador, through an analysis of its historical evolution, reforms, trends and differences in its constitutional and legal coverage, with respect to the generality of workers covered by the Labor Code. In this way, the objective is to provide a compilation and description of the national and international regulation of domestic work, from the definition of decent work, and the principle of equality and non-discrimination, as pillars for the creation of a fair and reasonable regulatory system. For this, a qualitative investigation is carried out, which based on the analytical-synthetic, inductive-deductive and historical-logical methods is able to create the necessary changes for the development of its constitutional protection.
\end{abstract}

Descriptors: Domestic work, Constitutional law, Principle of equality, Prohibition of discrimination, Reasonable justification.

\title{
INTRODUCCIÓN
}

Desde la Constitución del 2008, el estado ecuatoriano ha realizado importantes transformaciones tanto en su ordenamiento jurídico como en su organización política, que han irradiado en el funcionamiento y en la tutela de los derechos constitucionales, es por esto que, partiendo del régimen constitucional y legal vigentes sobre el servicio doméstico en el Ecuador, un estudio de sus actuales reglas debe tener como finalidad describir el ordenamiento jurídico positivo en el que se inserta esta modalidad especial de trabajo, con la intención de analizar a la luz de la Constitución de la República el grado de igualdad y discriminación que exterioriza, respecto de las normas generales reconocidas para el resto de trabajadores amparados por el Código del Trabajo. 
En este sentido, a pesar de que su regulación contemporánea sigue siendo un rezago que evidencia el mantenimiento de las jerarquías sociales, basadas en la subvaloración, el patriarcalismo, el mercado laboral, la discriminación, la informalidad y la invisibilidad de quienes realizan estos oficios, para los fines del presente estudio, se conceptualiza el servicio doméstico como aquel trabajo realizado dentro de los hogares necesario para el bienestar de sus miembros, ya sea que los trabajadores laboren a jornada completa o parcial, para un mismo empleador o varios, habiten en su morada o en su propia vivienda, sin que el empleador o su familia obtengan beneficio económico asociado con las tareas que realiza el trabajador o trabajadora doméstica (Sentencia $\mathrm{N}^{\circ}$ 227-12-SEP-CC, 2012).

Sin embargo, un estudio de las normas encaminadas a promover el trabajo doméstico necesariamente deberá ser complementado mediante definiciones que no solo regulen el trabajo decente, sino que también enmarquen esta modalidad especial de trabajo en mayores modelos de inclusión a través de los derechos de igualdad de trato y la prohibición de discriminación, con el objeto de que este segmento de trabajadores puedan ejercer plenamente sus derechos, en todas sus dimensiones, frente a presuntos tratos diferenciados no justificados que debido a una interpretación literal de las normas laborales, pueden presentarse al impedirse que se ejerzan los derechos de la delimitación y la subsistencia de sus contratos individuales de trabajo, en la misma medida en que estos son garantizados para la generalidad de trabajadores (Corte Constitucional del Ecuador, 2016).

En este contexto, la Constitución de la República y los instrumentos internacionales ratificados por el Ecuador al referirse al trabajo doméstico lo han enlazado con otros valores, como los inherentes a la dignidad de la persona humana, que en conjunto impiden la aplicación de cualquier diferenciación selectiva de los derechos, que sea capaz de transgredir la igualdad de oportunidades entre los sujetos. Con esta finalidad se plantea el problema de la presente investigación: ¿Cómo aplicar los principios de igualdad y la prohibición de discriminación en el servicio doméstico?, en consecuencia, 
el objetivo consiste en demostrar que los principios de igualdad y la prohibición de discriminación son aplicables en el servicio doméstico en el Ecuador.

\section{DESARROLLO}

\section{Evolución histórica y definición del servicio doméstico}

El servicio doméstico ha sido una labor que a lo largo de la historia se ha caracterizado por la transposición de las lógicas domésticas al mercado laboral, la subvaloración, el mantenimiento de las jerarquías sociales, la discriminación laboral, la informalidad y la invisibilidad de quienes realizan los oficios comprendidos dentro de esta modalidad de trabajo, que en su gran mayoría son mujeres y menores de edad, a los cuales, históricamente se les ha concedido condiciones más desfavorables que otros trabajadores remunerados, siendo uno de los sectores que presenta una mayor deuda de trabajo decente (Organización Internacional del Trabajo, 2009).

Así, partiendo de la alta subvaloración y vulnerabilidad del trabajo de las mujeres y menores de edad, así como, del rol que han desempeñado en la sociedad, los derechos de los trabajadores del servicio doméstico, serán reconocidos en el Ecuador de manera lenta pero progresiva, encontrando alrededor de los años 1930 y antes de 1938, la regulación del "contrato de arrendamiento", que después de tratar lo relativo al arrendamiento de cosas, casas y predios rústicos, se referirá al arrendamiento de criados y trabajadores asalariados en la legislación civil (Congreso de la República del Ecuador, 1930), según la cual, los trabajadores del servicio doméstico, serían denominados "criados o sirvientes domésticos" y el empleador llamado "amo", calificativos que se importarían de la época colonial.

De esta manera, el legislador establecerá un capítulo específico para regular el arrendamiento de criados y trabajadores asalariados, en el que, se reglamenta el contrato de arrendamiento de criados domésticos, el plazo de duración del instrumento, las formas de terminación, las indemnizaciones que los trabajadores estaban en la obligación de cancelar a su patrono, y este en ciertos presupuestos, y algo que se 
consideraría impensable en la realidad actual, que es la certeza casi incondicional del juramento del empleador en lo relativo a la prueba de la cuantía de la remuneración. No será, sino hasta el año de 1938, con la publicación del Código del Trabajo, en los Registros Oficiales Nro. 78 al 81, de fechas 14 al 17 de noviembre, que reguló la prestación de los servicios personales bajo la modalidad del contrato individual de trabajo, (aplicable a todos los trabajadores del sector privado, independientemente de la actividad que realicen), cuando las relaciones laborales del servicio doméstico, adquirirán las características básicas determinadas por las reglas generales establecidas en esta normatividad laboral, dejando obsoletos razonamientos como los anteriormente descrito, que posteriormente irán evolucionando en lo referente a los derechos de los trabajadores domésticos, y empezarán a impulsar las primeras normas que regularán las relaciones laborales del país, de ahí que, la primera definición que podemos encontrar en nuestro ordenamiento jurídico laboral, será la consagrada en el Código del Trabajo de 1938, que en su artículo 168, prescribía:

Art. 168. - Servicio doméstico es el que se presta mediante remuneración a una persona que no persigue fin de lucro y sólo se propone aprovechar, en su morada, de los servicios continuos del trabajo para sí solo o su familia, sea que el doméstico se albergue en casa del patrono o fuera de ella. En lo que no se hubiera previsto en el contrato se estará a la costumbre del lugar. (Jefe Supremo de la República, 1938, p. 12)

De manera semejante, el artículo 169 determinaría que: "El servicio doméstico comprende las labores de amas de llaves, nodrizas, cocineras, ayas, pajes, de las llamadas "criadas de mano" y más trabajos semejantes" (Jefe Supremo de la República, 1938 , p. 12), agregándose en su segundo inciso que: "No son domésticos sino trabajadores sometidos a las reglas generales de este Código, los que prestan sus servicios en hoteles, bares, fondas, posadas, hospitales o establecimientos análogos" (Jefe Supremo de la República, 1938, p. 12).

En esta línea, la primera cuestión que salta a la vista, la constituye la falta de protección de los trabajadores domésticos menores de edad, al haberse omitido una regulación sobre una edad mínima para el inicio del servicio, siendo necesario que transcurran 68 
años desde la expedición del Código del Trabajo, para que la Ley Nro. 39, publicada en el Registro Oficial Nro. 250, de fecha 13 de abril del 2006, modifique el artículo 262 (establecido por la regulación de 1938), al agregar como tercer inciso la siguiente frase:

La edad mínima para el trabajo doméstico será de quince años" (Congreso Nacional del Ecuador, 2006, p. 12), en concordancia con el numeral 3, del artículo 2 del Convenio Nro. 138 de la Organización Internacional del Trabajo, que al referirse a la edad mínima de admisión al empleo señala que: "La edad mínima fijada en cumplimiento de lo dispuesto en el párrafo 1 del presente artículo no deberá ser inferior a la edad en que cesa la obligación escolar, o en todo caso, a quince años" (Organización Internacional del Trabajo, 1976, p. 2).

Convirtiendo a esta reforma, en un claro ejemplo de un primer acuerdo por parte del gobierno, empleadores y trabajadores destinado a establecer unas condiciones mínimas internacionalmente señaladas para el mejoramiento de la vida de este segmento de trabajadores. De manera semejante, la Ley Nro. 39, publicada en el Registro Oficial Nro. 250, de fecha 13 de abril del 2006, por medio de la cual se expide la Ley Reformatoria al Código del Trabajo, establecerá condiciones generales de trabajo para los menores de edad, las cuales serán ampliadas mediante la Ley Nro. 00, publicada en el Registro Oficial Suplemento Nro. 797, de fecha 26 de septiembre del 2012, que contiene la Ley Orgánica para la Defensa de los Derechos Laborales.

La Ley 0, publicada en el Registro Oficial Suplemento Nro. 483, de fecha 20 de abril del 2015, por medio de la cual se dicta la Ley Orgánica para la Justicia Laboral y Reconocimiento del Trabajo en el Hogar, que si bien, serán analizadas en su conjunto, es la que realmente generaría un avance en materia de derechos laborales para los trabajadores domésticos, al reconocer una serie de derechos que no se habían planteado hasta ese momento.

No obstante, con la finalidad de realizar este análisis será necesario partir de las definiciones de servicio doméstico manejadas tanto a nivel nacional como la brindada por la Organización Internacional del Trabajo (2009), al afirmar que: "El trabajo doméstico consiste en actividades desempeñadas dentro de los hogares y necesarias 
para el bienestar de sus miembros" (p. 72), la definición anterior, sin embargo, no toma en cuenta la diversidad de tareas, ni las ambigüedades y dificultades tanto desde el punto de vista de la definición como de medición que pueden incluirse en ella, que hacen difícil conceptualizarlo (Gobierno de la República de México, 2016), por lo que, la enunciación que utilizaremos será la manejada en la legislación ecuatoriana, dado que este trabajo de investigación se enfoca a la realidad nacional.

En efecto, el ordenamiento jurídico ecuatoriano, al igual que otros países latinoamericanos, regula un capítulo especial en el Código del Trabajo en el que define esta actividad y los presupuestos particulares que aplica a esta modalidad de trabajo, diferenciándolo de las condiciones laborales determinadas para el resto de trabajadores. Así, el artículo 262 del Código del Trabajo señala que:

Art. 262. - Modalidades del servicio doméstico. - Servicio doméstico es el que se presta, mediante remuneración, a una persona que no persigue fin de lucro y sólo se propone aprovechar, en su morada, de los servicios continuos del trabajador, para sí solo o su familia, sea que el doméstico se albergue en casa del empleador o fuera de ella. En lo que no se hubiere previsto en el contrato, se estará a la costumbre del lugar. La edad mínima para el trabajo doméstico será de quince años. Para el caso de los adolescentes, se observarán las disposiciones contenidas en el Código de la Niñez y Adolescencia. (Congreso Nacional del Ecuador, 2015, p. 88)

No obstante, esta definición legal que relaciona la determinación del trabajo doméstico al espacio físico dentro del cual se presta el servicio, plantea una serie de problemas respecto de la ambigüedad de los límites de las actividades para las cuales pueden ser contratadas estos trabajadores, que usualmente, incluye labores de cocina, limpieza, atención de menores y adultos mayores, pero eventualmente también la ejecución de otras actividades, como apoyo de tareas escolares, limpieza de jardines, cuidado de animales, realizar las compras, entre otras, incluso la frase "sólo se propone aprovechar, en su morada, de los servicios continuos del trabajador, para sí solo o su familia" abre la posibilidad para que se creen circunstancias de requerimientos inmoderados de labores propias de la morada del empleador, lo que a su vez, se 
traduce en la mayoría de los casos en trabajo adicional a la jornada ordinaria, sin que pueda reclamarse judicialmente sus derechos (Ríos, 2000).

Por lo que, la referencia en el derecho internacional para tratar el tema objeto de esta investigación, como se ha señalado, será la Organización Internacional del Trabajo, que en el artículo 1 del Convenio Nro. 189 sobre el trabajo decente para las trabajadoras y los trabajadores domésticos, adoptado en Ginebra el 16 de junio del 2011, definirá las expresiones trabajo doméstico y trabajador doméstico de la siguiente manera:

A los fines del presente Convenio: a) la expresión "trabajo doméstico" designa el trabajo realizado en un hogar u hogares o para los mismos; (b) la expresión "trabajador doméstico" designa a toda persona, de género femenino o género masculino, que realiza un trabajo doméstico en el marco de una relación de trabajo; (c) una persona que realice trabajo doméstico únicamente de forma ocasional o esporádica, sin que este trabajo sea una ocupación profesional, no se considera trabajador doméstico. (Organización Internacional del Trabajo, 2013, p. 2)

Estas definiciones constantes en la Codificación del Código del Trabajo y en el Convenio Nro. 189, no solo incorporan bajo el amplio abanico del servicio doméstico, a un variado tipo de tareas relacionadas con el cuidado y el mantenimiento de una casa, independientemente de la necesidad que presenta o de sus características particulares, sino que también permiten deducir los elementos básicos y fundamentales que tipifican este tipo de contratos. Estos elementos son los siguientes:

a) El lugar de la actividad es un hogar privado, por lo que, las tareas están relacionadas con los servicios continuos del trabajador, respecto de la morada del empleador o su familia.

b) La tarea se ejecuta bajo la existencia de una relación de subordinación jurídica o dependencia, que se traduce en la facultad del empleador de dar instrucciones $u$ órdenes al trabajador, luego la subordinación se materializa por la obligación del trabajador, de mantenerse a las órdenes del empleador y de acatarlas a cambio de una remuneración. 
c) La vinculación de las tareas realizadas con aquellas inherentes al cuidado del hogar y de sus miembros, debiendo diferenciarse de las labores que se realicen en otros lugares (edificios, empresas, etc.), que no pueden ser consideradas como trabajo doméstico.

d) La ausencia de ganancia económica para el empleador (Organización Internacional del Trabajo, 2013).

Lo anterior no es sino una consecuencia genérica que define el servicio doméstico, pero en la realidad el sector cubre una serie de relaciones y condiciones de trabajo muy heterogéneas que, de presentar los elementos señalados en la legislación internacional, y en el artículo 262 del Código del Trabajo, presuponen la existencia de una relación laboral que debe regirse por las disposiciones contenidas en esta normativa. Así, la subordinación o dependencia será la característica determinante de esta relación de trabajo, por lo que, en caso de concurrir esta circunstancia, deberá materializarse el vínculo entre las partes a través de un contrato individual de trabajo (Organización Internacional del Trabajo, 2009).

\section{Análisis legal del régimen del servicio doméstico que se ha ido desarrollando con el pasar de los tiempos}

En este apartado se analiza el marco legal del servicio doméstico a nivel nacional, destacando la Ley 0, publicada en el Registro Oficial Suplemento Nro. 483, de fecha 20 de abril del 2015, por medio de la cual se expide la Ley Orgánica para la Justicia Laboral y Reconocimiento del Trabajo en el Hogar, que si bien marca avances importantes respecto de la relación capital-trabajo, entre los trabajadores domésticos y los empleadores, ampliando sus derechos laborales, mejorando sus condiciones de trabajo y acercándolos cada vez más a los trabajadores en general, todavía mantiene limitaciones en cuanto a su regulación, por lo que, este título está dedicado a reflejar los avances y limitaciones existentes en la misma. 
Otra normativa relacionada con el sector doméstico es la Ley Nro. 00, publicada en el Registro Oficial Suplemento Nro. 797, de fecha 26 de septiembre del 2012, por medio de la cual se expide la Ley Orgánica para la Defensa de los Derechos Laborales, que va ser tratada de manera más breve por cuanto la que realmente generó un avance en materia de derechos laborales para los trabajadores domésticos es la anteriormente señalada, al reconocer una serie de derechos no planteados hasta ese momento.

En esta línea, la primera cuestión a denotar la constituye el cambio legislativo producido a partir de la Ley Orgánica para la Justicia Laboral y Reconocimiento del Trabajo en el Hogar, inspirado en el Convenio Nro. 189, sobre el trabajo decente para los trabajadores y las trabajadoras domésticas llevado a cabo por la Organización Internacional del Trabajo, que dota de una apariencia de legitimación a los requerimientos de mayor igualdad laboral de las y los trabajadores domésticas, y modifica las condiciones labores de este sector establecido hasta ese momento por la regulación del Código del Trabajo de 1938, que si bien a partir de la Ley Orgánica para la Defensa de los Derechos Laborales, pasaron a considerarse realmente laborales, mantenía una serie de articulados que generaban un proceso de discriminación laboral, en relación al resto de trabajadores (Valiente, 2016).

Tanto es así, que la Ley Orgánica para la Justicia Laboral y Reconocimiento del Trabajo en el Hogar, es el resultado de muchos años de lucha por dignificar el sector doméstico y equiparar sus condiciones con las de los demás ámbitos profesionales, conforme la protección especial establecida en el artículo 325 de la Constitución de la República, que reconoce todas las modalidades de trabajo en relación de dependencia o autónomas, con inclusión de labores de auto sustento y cuidado humano; y como actores sociales productivos, a todas las trabajadoras y trabajadores.

Dicha ley orgánica entre varios aspectos procedió a modificar en quince días el período de prueba para el caso de los contratos de servicio doméstico o trabajo remunerado del hogar, generándose una relación laboral de carácter especial del servicio doméstico en el hogar, por otra parte, entre los aspectos positivos valorados se encuentra la 
derogatoria del artículo 264 del Código del Trabajo, la sustitución de los artículos 111 y 113 que garantizan a los empleados y trabajadores domésticos los mismo beneficios en lo relativo a las remuneraciones adicionales de cualquier otro trabajador en general y la sustitución del artículo 265 por el siguiente: "Una vez vencido el período de prueba, se convierte en un contrato por tiempo indefinido. En caso de despido intempestivo, para el cómputo de la indemnización, se tomará en cuenta la remuneración que perciba la persona trabajadora" (Asamblea Nacional del Ecuador, 2015, p. 89), que, al no regular un tiempo máximo de duración del contrato de servicio doméstico, implica directamente una mejora en las condiciones del trabajo al presumirse su carácter indefinido una vez vencido el periodo de prueba.

Habría que decir también, que la anterior regulación del artículo 265, al disponer en su tercer inciso que: "En caso de despido intempestivo, para el cómputo de la indemnización, se tomará en cuenta únicamente la remuneración en dinero que percibía el doméstico" (Asamblea Nacional del Ecuador, 2015, p. 13), se alejaba de la defensa de los estándares del principio de igualdad y no discriminación en el empleo que presuponía la aplicación de este artículo y su adecuación a la legislación constitucional. Otra modificación positiva de la legislación ordinaria reside en la derogatoria expresa de previsiones normativas que en general privilegiaban en forma excesiva la posición contractual de la parte empleadora, al punto de establecer disposiciones contrarias al principio de la dignidad humana, así como, a los derechos a la igualdad, no discriminación y al derecho a la libertad, como aquella contenida en el artículo 266 del Código del Trabajo que permitía obligar al trabajador doméstico a permanecer en el servicio a pesar de su renuncia, hasta que pudiera garantizarse su reemplazo y tomando como único criterio el interés personal del empleador (Asamblea Nacional del Ecuador, 2015).

En estas condiciones, las expresiones formuladas en la norma derogada son hoy un rezago de la forma como se regulaba el vínculo entre el empleador y el trabajador doméstico, tanto es así que, mediante resolución del anterior Tribunal de Garantías 
Constitucionales, publicada en el Registro Oficial Nro. 535, del 3 de octubre de 1990, ya en aquella época se suspendió en forma total los efectos de este artículo, al considerar que violaban por el fondo las disposiciones contendidas en el inciso 2, de los numerales 11 y 12, del artículo 19 de la Constitución Política de la República de 1978 (Resolución. Abg. Efraín Álvarez Fiallo. Presidente Encargado del Tribunal de Garantías Constitucionales, 1990).

No obstante, será la Corte Suprema de Justicia la que revoque la suspensión de inconstitucionalidad del artículo 261, mediante resolución publicada en el Registro Oficial No. 299 de fecha 19 de octubre de 1993, al estimar que el contenido del mismo no entrañaba en su fondo, un atentado o violación a los preceptos constitucionales, ni convenios o acuerdos internacionales válidamente ratificados por el Ecuador, considerando simplemente que se trataba de:

(...) un precepto que fluye de la naturaleza y fines del propio contrato individual de trabajo, definido en el artículo 8 de la Ley de la Materia, donde existen deberes y derechos recíprocos entre trabajador y empleador; caso contrario de admitirse el retito inopinado del trabajador, generaría en determinadas circunstancias como: asistencia en enfermedad, cuidado de menores, etc..., graves e impredecibles consecuencias, lesionando derechos garantizados por la Constitución que no pueden ser excepción cuando el agraviado fuese el empleador. (Sentencia Nro. 13/93, 1993, p. 23)

Lo que por sí solo demuestra un anacronismo social que tiene consecuencias decisivas sobre la declaratoria de constitucionalidad del artículo 261 del Código de Trabajo, dada la injusta y peyorativa interpretación que comporta, que posteriormente sería solventada mediante la derogatoria formulada por el legislador a través de la Ley Orgánica para la Justicia Laboral y Reconocimiento del Trabajo en el Hogar.

En cuanto al tiempo de trabajo, el rasgo diferenciador más característico respecto a otros sectores se encontraba relacionado con la disposición contenida en el artículo 269 Ibidem, que permanecía de la regulación de 1938 y que al señalar que los domésticos tienen derecho a un día de descanso cada dos semana de servicio, determinaba periodos de descanso inferiores a los establecidos en la ley para los trabajadores en 
general, a esta restricción la Ley Orgánica para la Defensa de los Derechos Laborales, añadió después del artículo 268 el siguiente artículo innumerado:

Art. ... .- A los empleados y trabajadores domésticos se garantiza los mismos beneficios de cualquier otro trabajador en general, debiendo sus jornadas de trabajo y descanso ser de cinco días a la semana o sea cuarenta horas hebdomadarias y los días sábados y domingos serán de descanso. Si en razón de las circunstancias, no pudiere interrumpirse el trabajo en tales días, se designará otro tiempo igual de la semana para el descanso, mediante acuerdo entre empleador y trabajadores. (Asamblea Nacional del Ecuador, 2012, p. 6)

Incrementando el número de días de descanso en el computo semanal, así como, períodos compensatorios de reposo en el evento de que no se pudiere interrumpir el trabajo en tales días, siempre que medie el común acuerdo entre las partes, cuanto más, se han ajustado los beneficios a aquellos establecidos para los demás trabajadores.

En este punto vale la pena referirnos al servicio doméstico asociado a los menores de edad, pues en el Ecuador no fue sino hasta la expedición del Código de Trabajo en el año de 1938, cuando se prohíba el trabajo nocturno para mujeres y varones menores de dieciocho años, donde se podrá apreciar una normativa en tal sentido, a pesar de su naturaleza excluyente, porque dentro de ese mismo grupo de menores, se estableció una excepción para los que tuvieran como labor dedicarse al servicio doméstico, pues les estaba permitido trabajar en jornadas nocturnas.

En este sentido, será necesario un avance legislativo por medio de la ley Nro. 133, publicada en Registro Oficial Suplemento Nro. 817 del 21 de noviembre de 1991, a través de la cual se expide la Ley Reformatoria al Código del Trabajo, para que se extienda este derecho al grupo de menores de edad al eliminarse la frase "(...) con excepción del servicio doméstico" (Congreso Nacional del Ecuador, 1991, p. 7).

Posteriormente con la Ley Nro. 39, publicada en el Registro Oficial Suplemento Nro. 250, de fecha 13 de abril del 2006, por medio de la cual se expide la Ley Reformatoria al Código del Trabajo, se establecerán condiciones generales de trabajo para los 
menores de edad. Con esta ley encontramos como el legislador le da total importancia y trascendencia al factor de la edad y a los derechos a la educación básica, alimentación, salud, recreación y descanso, dejando de lado el tipo de actividad, lo cual sin duda constituye una humanización del trabajo de los menores de edad (Nuvaez Castillo, 2019a).

Desde entonces y hasta el momento, la restricción para el trabajo de los menores de edad estará relacionada con la edad y el bienestar del trabajador, de manera que el empleador en el caso de los adolescentes que han cumplido quince años está en la obligación de observar las disposiciones contenidas en el Código de la Niñez y Adolescencia e independientemente de la remuneración que se fije deberá proporcionar al doméstico alimentación y albergue, a menos que exista pacto en contrario. Cuanto más, dentro de sus posibilidades y de la limitación que impone el servicio deberá propender de la mejor manera posible a la educación básica, salud, recreación y descanso del menor de edad (Nuvaez Castillo, 2019b).

Es así que, a pesar de la lentitud en la progresividad de los derechos laborales a favor de los trabajadores domésticos, podemos señalar que en los últimos ochenta años, (desde 1930 cuando ya encontrábamos regulados el arrendamiento de criados y trabajadores asalariados desde la legislación civil), ha existido una evolución positiva en torno a la regulación y protección de sus derechos, que les ha permitido gozar de la extensión de garantías y beneficios que solo fueron concebidos en principio a los demás trabajadores en general, aun cuando todavía existen serios problemas de trabajo decente, que requieren de un mayor reconocimiento social, una revaloración de su aporte a la economía y una nueva preocupación del Estado por los derechos laborales de estos segmentos de trabajadores (Tamayo Vásquez \& Pino Loza, 2019). 


\section{Protección legal de las y los trabajadores de servicio doméstico desde el principio de igualdad y la prohibición de discriminación}

El estudio realizado, nos ofrece información sobre la regulación que a nivel ordinario se ha dictado respecto del trabajo doméstico, así mismo, permite determinar los anacronismos que existieron y aún se aprecian en el estado ecuatoriano en comparación con los derechos reconocidos para otros sectores laborales, por lo que, con la finalidad de establecer una propuesta válida que, si bien no pretende solucionar de raíz el problema planteado, examinaremos la protección legal de este segmento de trabajadores desde el derecho de igualdad y la prohibición de no discriminación, que consagrado en la Constitución de la República, sostienen la necesidad de considerar a toda diferenciación no razonable o arbitraria como discriminatoria y por lo mismo violatorio del derecho a la igualdad (Ministerio de Justicia, Derechos Humanos y Cultos, 2010).

En virtud de aquello justificar la diferenciación selectiva de los derechos, que por regla general deberían tener una trascendencia universal, requiere reconocer la naturaleza del principio a la igualdad como principio constitucional sustantivo (artículo 66, numeral 4), pero también como principio de aplicación e interpretación de los demás derechos constitucionales, (artículo 11, numeral 2), lo que significa, que esta consagración, acepta que el derecho a la igualdad, tiene dos dimensiones claramente identificadas, la igual aplicación de la ley, en sentido formal, y la igualdad material, que conjuntamente con el principio de no discriminación, impiden la generación de privilegios a determinados sujetos de derechos y evitan las desigualdades subjetivas que de hecho existen entre las personas (Corte Constitucional del Ecuador, 2016).

A este respecto, la Corte Constitucional, al interpretar el derecho a la igualdad y la prohibición de no discriminación reconocido en el artículo 11, numeral 2 de la Constitución de la República, ha señalado lo siguiente:

Resulta claro para esta Corte, en primer lugar, que todas aquellas "distinciones" que se fundan en los criterios expuestos en la norma constitucional del artículo 11 numeral 2 de la Constitución de la República, 
prima facie son inconstitucionales a menos que se demuestre lo contrario, dada la carga argumentativa y probatoria que implica justificar para quienes establecen un trato diferente que el mismo es razonable y proporcional; $y$ en segundo lugar, solo una justificación razonable exime a quienes hayan establecido distinciones, de la responsabilidad de que pueda imputárseles un tratamiento discriminatorio. (Sentencia Nro. 080-13-SEP-CC, 2013, p. 16)

De donde resulta particularmente interesante para el tema, la adhesión de la Corte Constitucional, al principio de no discriminación como un acto de proporcionalidad y razonabilidad de las medidas utilizadas por el Estado, que enlazado con los valores inherentes a la dignidad de la persona humana, permite aplicar una diferenciación selectiva de los derechos, que sea capaz de transgredir la igualdad de oportunidades entre los sujetos, siempre que el trato diferenciado no se funde en una de las categorías enunciadas en el artículo 11, numeral 2 de la Constitución, que al estar protegidas, no pueden ser usadas para justificar la constitucionalidad de la diferencia (Valiente, 2010), pues que, cuando la desigualdad jurídica de trato se fundamenta en criterios tales como la etnia, el lugar de nacimiento, la edad, el sexo, la identidad de género, etc., la igualdad se convierte en un juicio muy riguroso, en la que, no es aplicable la doctrina de la clasificación razonable sino la denominada doctrina de la clasificación sospechosa (Universidad Nacional Autónoma de México, 2015).

Esta definición, por lo tanto, independientemente de sus valoraciones y discusiones semánticas, abarca tanto las discriminaciones negativas, es decir, que se producen cuando incumpliendo las previsiones científicas o disposiciones legales se causa un daño o resultado perjudicial, pero también, las discriminaciones positivas que buscan beneficiar a un grupo de individuos de acuerdo a sus peculiaridades, pero sin perjudicar a quienes aún no lo son (Sentencia Nro. 048-13-SCN-CC, 2013).

Para ilustrarlo mejor, aplicando estas nociones a la situación que se considera problemática, resulta oportuno señalar que el artículo 262 del Código del Trabajo, al definir el servicio doméstico como la actividad: 
(...) que se presta, mediante remuneración, a una persona que no persigue fin de lucro y sólo se propone aprovechar, en su morada, de los servicios continuos del trabajador, para sí solo o su familia, sea que el doméstico se albergue en casa del empleador o fuera de ella. (Congreso Nacional del Ecuador, 2015, p. 88)

Constituye una de las principales causas que generan las arbitrariedades a las que están expuestos las y los trabajadores que se encuentran comprendidos en esta enunciación ambigua de actividades que establece la ley y que determina el empleador, en relación con el conjunto de derechos reconocidos y aplicables al régimen general del Código del Trabajo, en la medida en que el diseño de la norma analizada evidentemente comporta una restricción de los derechos de estos trabajadores, respecto de otros sectores en los que las funciones están claramente delimitadas y las posibilidades de confusión o conflicto se ven restringidas (Macassi, 2001).

Así pues, en el presente caso, se evidencia un tratamiento jurídico diferenciado, no justificado respecto de la falta delimitación de las actividades y condiciones particulares que se aplican a esta categoría de trabajadores, que están en situación de comparabilidad, con las condiciones laborales establecidas para el resto de trabajadores amparados por el Código del Trabajo, que tienen claramente limitadas sus labores a las actividades para las cuales son contratados, encontrándonos frente a un escenario de precarización laboral y vulneración del derecho constitucional a la igualdad en su dimensión material, que como sabemos, busca la efectividad de todos los derechos constitucionales, independientemente de la categoría a la que pertenezcan.

Dado que, estos razonamientos de igualdad material, no solamente requieren de una igual aplicación de la ley, sino también la necesaria protección del Estado, para crear las condiciones materiales propicias para su pleno ejercicio, frente a una inexistente enumeración de las labores que se pueden realizar y la ausencia de una protección legal respecto de la elasticidad y simultaneidad de las tareas, que en muchos casos dependen de los gustos y rutinas de los integrantes de la familia (Pérez, 2007). 
Así, dentro del caso sometido a estudio la disposición contenida en el artículo 262 del Código del Trabajo, se muestra manifiestamente inconstitucional y discriminatoria, toda vez que no contempla la misma protección garantizada en el artículo 33 de la Constitución a todas las personas trabajadoras, que ya sean del servicio doméstico o de otras ramas de actividad, tienen derecho a que se les consigne normativa y contractualmente, la clase o clases de tareas que serán objeto de la relación individual de trabajo, contraviniéndose con esta omisión el artículo 11, numeral 2, artículos 33, 66 numerales 2 y 4 de la Constitución, así como, el artículo 1, del Convenio Nro. 111, sobre la discriminación en el empleo y la ocupación, y su Recomendación Nro. 111, el artículo 3, numeral 2, literal d) del Convenio Nro. 189 sobre el trabajo decente para las trabajadoras y los trabajadores domésticos de la Organización Internacional del Trabajo, y el artículo 11, numeral 2 de la Convención sobre la eliminación de todas las formas de discriminación contra la mujer.

Por tanto, se reflexiona que la aplicación de dicha norma no tiene una justificación razonable y más bien vulnera el derecho a la igualdad y no discriminación. Finalmente, sobre la base del examen realizado, y acorde a las ideas expuestas, se puede señalar que tampoco existen un fundamento objetivo y razonable, de acuerdo con la finalidad perseguido por el legislador, que justifiquen la vulneración del derecho a la subsistencia del contrato laboral de los trabajadores de servicio doméstico regulado en el artículo 169, numeral 4 del Código de Trabajo, mediante la disposición contenida en el artículo 267 Ibidem, que al referirse al fallecimiento del empleador establece que los herederos deberán mantener el contrato, salvo en el caso de que el empleador hubiere manifestado lo contrario (Vázquez, 2018).

Así, la interpretación que restringe el acceso a la subsistencia del contrato se muestra como una afectación innecesaria, por cuanto, la normativa general claramente prescribe que en el evento de fallecimiento del empleador el contrato termina cuando no exista representante legal o sucesor que continúe al frente de la empresa o negocio y sea imposible prolongar la relación laboral con los sucesores o ellos no quieran tomar a su 
cargo la empresa, sin que esta circunstancia quede al árbitro de una manifestación de voluntad del empleador, por lo que, considerando que estas disposiciones no son conciliables con el derecho a la igualdad, se hace necesario elaborar un proyecto de ley que reforme estas disposiciones con el objetivo de sistematizar una legislación ordinaria sobre los trabajadores del servicio doméstico que contemple las normas constitucionales, los convenios y tratados internacionales, en procura del desarrollo del contenido de estos derechos.

Finalmente, luego del análisis realizado, se estima pertinente, mostrar al lector, la propuesta que se pretende plantear a la luz del principio de igualdad de trato y la prohibición de discriminación:

a) la limpieza general de la casa particular o de familia,

b) el cuidado de hijas o hijos menores de edad,

c) el cuidado de adultos mayores o personas con discapacidad

(acompanamiento)

d) la preparación de comida para consumo del empleador o su

familia,

e) las que versen sobre trabajos que no requieran de conocimientos

técnicos o capacitación especifica,

D todes las tareas que se ejecute en la casa panteular o de ta tamila

del empleador y que no imvolucre lucro o beneficio económico directo

para este último.

g) en general la ejecución de servicios que usualmente se prestan

fuera del espacio fisico de la morada del empleado

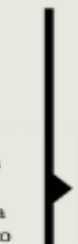

.

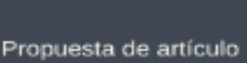

Promover la creación de contratos individuales de trabajo, para el servicio doméstico, con los mismos derechos que establecen los contratos de trabajo

establecen los contratos
generales.

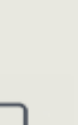

(n)




\section{METODOLOGÍA}

Por otra parte, fundamentados en un enfoque cualitativo la información sobre el problema de investigación, se basó en los procesos analítico-sintético e inductivodeductivo que desempeñaron un papel importante en el desarrollo de la teoría al permitirnos categorizar los principales avances, causas, vinculaciones y reflexiones, para la posterior exploración, descripción y generalización de estas perspectivas teóricas sobre el servicio doméstico (Hernández, 2014). Así como, en un proceso de recopilación de datos mediante fuentes primarias, como: normas constitucionales, convenios internacionales, leyes, reglamentos, sentencias, publicaciones, documentos técnicos e informes de instituciones públicas nacionales, que fueron complementados con fuentes secundarias, provenientes principalmente de investigaciones elaboradas por instituciones internacionales como la Organización Internacional del Trabajo (OIT), el Centro de Documentación y Estudio (CDE) y la ONU Mujeres, así como, información creada por agencias especializadas emparentadas con el amparo de los derechos de las y los trabajadores domésticos (Santos, Narváez, Erazo y Machuca, 2019).

\section{APORTES}

Los estudios que contiene este trabajo muestran, que el servicio doméstico remunerado está adquiriendo un nuevo estatus en el país. Aun cuando todavía se lo considera una modalidad particular de trabajo, regida por nomas específicas que modifican el régimen general y tienen el carácter de crear una serie de problemas de trabajo decente, su reconocimiento vislumbra un mayor reconocimiento social, una revaloración de su aporte a la economía y una nueva preocupación del Estado por los derechos laborales de estos trabajadores.

En este contexto, de conformidad con la Constitución de la República, los Tratados y Convenios Internacionales, el país ha puesto en práctica diversas iniciativas para mejorar sus condiciones de trabajo, aumentar el cumplimiento de la ley que los ampara y equiparar sus derechos laborales con los del resto de trabajadores, siendo varios los 
elementos que sustentan la necesidad de adecuar la normativa vigente, relacionada a la modalidad de trabajo del servicio doméstico, con la legislación común de los trabajadores, que dentro de la denominada constitucionalización del derecho del trabajo, busca una generalización de la legislación laboral, que garantice a los trabajadores condiciones más favorables y equipare las cargas sociales, con el objeto de evitar un tratamiento jurídico diferenciado injustificado de las diversas modalidades laborales contempladas en el Ecuador.

Es así que, con fundamento en el artículo 11, numeral 2, artículos 33, artículo 66 numerales 2 y 4 de la Constitución, el artículo 1, del Convenio Nro. 111, sobre la discriminación en el empleo y la ocupación, y su Recomendación Nro. 111, el artículo 3, numeral 2, literal d) del Convenio Nro. 189 sobre el trabajo decente para las trabajadoras y los trabajadores domésticos de la Organización Internacional del Trabajo, y el artículo 11, numeral 2 de la Convención sobre la eliminación de todas las formas de discriminación contra la mujer, por ser una labor que a nivel general se hace mayoritariamente por mujeres, en los últimos años el Ecuador ha realizado diferentes modificaciones legales para avanzar en la equiparación de derechos de los trabajadores del servicio doméstico.

El caso más notable es la Ley Orgánica para la Justicia Laboral y Reconocimiento del Trabajo en el Hogar, que otorga a los trabajadores domésticos un marco normativo similar al del resto de trabajadores, incluyendo su derecho a mantener contratos indefinidos, remuneraciones adicionales, indemnizaciones por despido intempestivo, vacaciones y días de descanso. Estos esfuerzos apuntan a modificar la diferencia en el trato legal del servicio doméstico, que tenían como consecuencia la negación de una serie de derechos que la ley consagra al resto de trabajadores.

No obstante, a pesar de estos avances positivos aún persisten circunstancias que requieren especial atención, por sustentarse en categorías sospechosas de discriminación, que traen inmersas la necesidad de establecer una regulación que no comporte una restricción de los derechos constitucionales de las y los trabajadoras del 
servicio doméstico, a los cuales, sin ninguna justificación se les ha desprotegido respecto de la generalidad de trabajadores amparados por el Código del Trabajo, debido al trato diferenciado regulado en relación a su derecho a la delimitación de las particularidades de su servicio y la subsistencia de sus contratos individuales de trabajo. De ahí que, con la finalidad de solucionar estos problemas, unificar conceptos y otorgar a los trabajadores domésticos las mismas garantías con las que cuentan el resto de los trabajadores dependientes, se propone desde estas líneas, la elaboración de un proyecto de ley reformatoria del Código del Trabajo, que contemple aspectos como: la obligatoriedad del trabajo doméstico únicamente en el ámbito de la casa particular o de la familia del empleador, la delimitación necesaria de las actividades para las cuales pueden ser contratadas estos trabajadores, y la subsistencia de sus contratos individuales de trabajo, en la misma medida en que estos son garantizados para la generalidad de trabajadores amparados por las normas laborales.

En este sentido, se recomienda la redacción de un artículo que enumere las actividades para las cuales pueden ser contratadas estos trabajadores, que en base a las labores que usualmente realizan, contemple tareas como: a) la limpieza general de la casa particular o de familia, b) el cuidado de hijas o hijos menores de edad, que no involucre su educación formal, c) el cuidado de adultos mayores o personas con discapacidad, siempre que no implique la realización de labores médicas o paramédicas, ni la limpieza o aseo de los mismos, sino exclusivamente su acompañamiento en el ámbito del hogar, d) la preparación de comida para consumo del empleador o su familia, e) las que versen sobre trabajos que no requieran de conocimientos técnicos o capacitación específica, f) todas las tareas que se ejecute en la casa particular o de la familia del empleador y que no involucre lucro o beneficio económico directo para este último, y, g) en general la ejecución de servicios que usualmente se prestan fuera del espacio físico de la morada del empleador, que incluyan las tareas inherentes al mismo, tales como, la realización de compras diarias, el traslado de menores de edad de la escuela, la sujeción a las órdenes del empleador o de su familia, entre otras labores análogas. 
De donde resulta que, un proyecto de ley de esta naturaleza, también debería adoptar una regulación única en lo relativo a la subsistencia del contrato de este segmento de trabajadores, que sea capaz de eliminar las desigualdades existentes, con miras hacia una estandarización de las condiciones y términos de trabajo y evitar la excepción normativa actual que vulnera el derecho de igualdad y la prohibición de discriminación reconocidos como derechos constitucionales y elementos básicos del Estado Constitucional de Derechos y Justicia, pues el artículo 169 del Código del Trabajo prescribe que en el evento de fallecimiento del empleador el contrato termina cuando no exista representante legal o sucesor que continúe al frente de la empresa o negocio y sea imposible prolongar la relación laboral con los sucesores o ellos no quieran tomar a su cargo la empresa, sin que esta circunstancia tal como se encuentra redactado el artículo 267 del Código del Trabajo, pueda quedar al árbitro de una manifestación de voluntad del empleador.

Paralelamente, en este punto puede también recalcarse el importante papel que cumplen las inspectorías del Trabajo, en defensa de los derechos laborales de los trabajadores domésticos, a través de campañas de información y promoción del cumplimiento de la ley o de las labores de control que se desarrollan mediante el sistema de denuncias y procedimiento de vigilancia, así como, de multas y sanciones, que acompañados del conocimiento de la ley y la confianza en las instituciones públicas, han sido pilares fundamentales para que los trabajadores hagan uso de los mecanismos legales y administrativos que les ampara. Es así que, el Ministerio del Trabajo ha llevado a cabo una serie de procesos de capacitación a inspectores y mediadores sobre trabajo digno que ha tenido como resultado una mejor y más rápida solución de los conflictos.

\section{REFERENCIAS CONSULTADAS}

1. Asamblea Nacional del Ecuador. (26 de Septiembre de 2012). Ley orgánica para la defensa de los derechos laborales. Registro Oficial Suplemento 797. Quito, Pichincha, Ecuador. 
2. Asamblea Nacional del Ecuador. (20 de Abril de 2015). Ley Orgánica para la Justicia Laboral y Reconocimiento del Trabajo en el Hogar. Registro Oficial Suplemento Nro. 48. Quito, Ecuador.

3. Congreso de la República del Ecuador. (20 de Junio de 1930). Código Civil. Registro Oficial Suplemento Nro. 352. Quito, Ecuador.

4. Congreso Nacional del Ecuador. (21 de Noviembre de 1991). Ley Reformatoria al Código del Trabajo. Quito, Pichincha, Ecuador.

5. Congreso Nacional del Ecuador. (13 de Abril de 2006). Ley Reformatoria al Código del Trabajo. Registro Oficial Suplemento Nro. 250. Quito, Ecuador.

6. Congreso Nacional del Ecuador. (16 de Diciembre de 2015). Código del Trabajo. Registro Oficial Suplemento Nro. 167. Quito, Pichincha, Ecuador.

7. Corte Constitucional del Ecuador. (2016). Desarrollo Jurisprudencia de la primera Corte Constitucional. Quito: Centro de Estudios y Difusión del Derecho Constitucional.

8. Gobierno de la República de México. (2016). El trabajo doméstico en México: La gran deuda social. Mexico: Secretaría del Trabajo y Previsión Social.

9. Hernández Sampieri, R. (2014). Metodología de la Investigación. México: INTERAMERICANA EDITORES, S.A. DE C.V.

10. Jefe Supremo de la República. (14 al 17 de Noviembre de 1938). Código del Trabajo. Registros Oficiales Nro. 78 al 81. Quito, Pichincha, Ecuador.

11. Macassi Leon, I. (5 de Diciembre de 2001). Regímenes Jurídicos sobre trabajo doméstico remunerado en Colombia, Ecuador, Perú y Venezuela. Obtenido de www.cotidianomujer.org.uy/domesticas_4p.pdf

12. Macassi, I. (5 de Diciembre de 2001). Regímenes Jurídicos sobre trabajo doméstico remunerado en Colombia, Ecuador, Perú y Venezuela. Obtenido de www.cotidianomujer.org.uy/domesticas_4p.pdf

13. Ministerio de Justicia, Derechos Humanos y Cultos. (2010). Igualdad y no discriminación. El reto de la diversidad. Quito: Ministerio de Justicia, Derechos Humanos y Cultos. 
14. Nuvaez Castillo, J. (2019a). La discriminación laboral en razón del género y la edad en Colombia. Revista Arbitrada Interdisciplinaria Koinonía, 4(7), 308-326. doi:http://dx.doi.org/10.35381/r.k.v4i7.207

15. Nuvaez Castillo, J. (2019b). Alcance sociocultural de la discriminación laboral en razón del género y la edad. IUSTITIA SOCIALIS, 4(6), 4-27. doi:http://dx.doi.org/10.35381/racji.v4i6.286

16. Organización Internacional del Trabajo. (19 de Junio de 1976). Convenio Nro. 138. Sobre la edad mínima. Ginebra, Suiza.

17. Organización Internacional del Trabajo. (2009). Trabajo doméstico: un largo camino hacia el trabajo decente. (M. E. Valenzuela, \& C. Mora, Edits.) Santiago: Oficina Internacional del Trabajo.

18. Organización Internacional del Trabajo. (05 de Septiembre de 2013). Convenio Nro. 189. Sobre el trabajo decente para las trabajadoras y los trabajadores domésticos. Ginebra, Suiza.

19. Organización Internacional del Trabajo. (2013). Manual de buenas prácticas para trabajadoras y empleadoras del servicio doméstico (Primera ed.). Santiago: Organización Internacional del Trabajo.

20.Pérez Luño, A. E. (2007). Dimensiones de la igualdad (Segunda ed.). (R. González-Tablas Sastre, Ed.) Madrid: DYKINSON, S.L.

21. Resolución. Abg. Efraín Álvarez Fiallo. Presidente Encargado del Tribunal de Garantías Constitucionales, Caso Nro. 416/89-2 (Tribunal de Garantías Constitucionales del Ecuador 24 de Septiembre de 1990).

22. Ríos Estavillo, J. J. (2000). Derechos de los trabajadores domésticos (Primera ed.). México: Universidad Nacional Autónoma de México.

23. Santos Cabrera, J. G., Narváez Zurita, C. I., Erazo Álvarez, J. C., \& Machuca Contreras, M. d. (2019). La planificación tributaria como mecanismo de eficiencia económica en el tratamiento del impuesto a la renta. Cienciamatria, 683.

24. Sentencia Nro. 048-13-SCN-CC, 0179-12-CN y ACUMULADOS (Corte Constitucional del Ecuador 04 de Septiembre de 2013). 
25. Sentencia Nro. 080-13-SEP-CC, Caso Nro. 0445-11-EP (Corte Constitucional del Ecuador 09 de Octubre de 2013).

26. Sentencia Nro. 13/93 (Corte Suprema de Justicia del Ecuador. Sala de lo Constitucional 20 de Julio de 1993).

27. Tamayo Vásquez, F., \& Pino Loza, E. (2019). Derechos Humanos de los niños, niñas y adolescentes en los procesos Arbitrales. IUSTITIA SOCIALIS, 4(7), 97114. doi:http://dx.doi.org/10.35381/racji.v4i7.357

28. Universidad Nacional Autónoma de México. (2015). Enciclopedia de filosofía y teoría del derecho (Vol. II). (J. L. Fabra Zamora, \& V. Rodríguez Blanco, Edits.) México: Instituto de investigaciones jurídicas.

29. Valiente, H. (2010). Régimen jurídico sobre el trabajo doméstico, remunerado en los estados de MERCOSUR. Edición revisada y ampliada. Montevideo: Cotidiano Mujer.

30. Valiente, H. (2016). Las leyes sobre trabajo doméstico remunerado en América Latina. Asunción: Centro de Documentación y Estudios (CDE) y ONU Mujeres.

31.Vázquez, D. (2018). Test de razonabilidad y derechos humanos: instrucciones para armar. Restricción, igualdad y no discriminación, ponderación, contenido esencial de derechos, progresividad, prohibición de regresión y máximo uso de recursos disponibles. México: Instituto de investigaciones jurídicas. 